\title{
CAOSGRAFIA DO AMOR DOCENTE
}

Verônica Domingues Almeida

\section{Resumo}

Apresenta-se, neste artigo, a caosgrafia, uma metodologia criada em uma pesquisa de Doutorado em Educação. Tendo como temática amor e docência, o objetivo foi tensionar a vinculação do amor a representações cristalizadas e a juízos de valor que impõem perfis à profissão, de modo a desvelar paisagens da docência, esboçadas por professores no Facebook®. Engendrada em uma postura complexa e multirreferencial, estabelecida entre a Bricolagem de Lévi-Strauss, bem como a ampliação de Kincheloe e Berry e a Geofilosofia de Deleuze e Guattari, a caosgrafia empreendeu uma bricolagem acêntrica, construída em ensaios metodológicos, delineados por um mapa - roteiro-esboco-coreografias - que contemplou o atravessamento de referências heterogêneas sobre o amor, as quais coabitam na contemporaneidade e ressoam no campo da educação. Como resultados, apresentam-se duas paisagens de amor e docência no Facebook®: "Bailes dos 15 de outubro" e "Focos de abominação a Paulo Freire". Propõe-se, ainda, que se fundem novas éticas amorosas, efetivadas no esteio de uma educação para as relações.

Palavras-chave: amor; docência; metodologia de pesquisa.

\section{CHAOSGRAPHY OF TEACHER LOVE}

Abstract

It is presented, in this paper, the chaosgraphy, a methodology created in a Doctoral research in Education. With the theme of love and teaching, the objective was to tension the link of love to crystallized representations and value judgments that impose profiles on the profession, in order to show landscapes of teaching, sketched by teachers on Facebook ${ }^{\circledR}$. Engendered in a complex and multi-referential stance, established between Lévi-Strauss's bricolage, as well as the enlargement of Kincheole and Berry, and Deleuze and Guattari's Geo-philosophy, the chaosgraphy developed an acentric bricolage, built methodological essays, delineated by a map - script-outline-choreographies - that contemplated the crossing of heterogeneous references about love, which co-habit in the contemporaneity and resonate in the field of Education. As a result, love and teaching landscapes on Facebook ${ }^{\circledR}$ are presented: "Dances of the October 15th" and "Abomination focus to Paulo Freire". It is also proposed that new loving ethics are founded, developed as pillar of education to relationships.

Keywords: love; teaching; research methodology.

\section{CAOSGRAFÍA DEL AMOR DOCENTE}

\section{Resumen}

En este artículo se presenta la caosgrafía, una metodología creada en una investigación de Doctorado en Educación. Teniendo como temática el amor y la docencia, el objetivo fue tensionar la vinculación del amor a las representaciones cristalizadas y a juicios de valor que imponen perfiles a la profesión, de modo a exhibir paisajes de la docencia, expuestas por profesores en Facebook. ${ }^{\circledR}$. Engendrada en una postura compleja y multirreferencial, establecida entre el Bricolaje de Lévi-Strauss, así como la ampliación de Kincheloe y Berry, y la Geofilosofia de Deleuze y Guattari, la caosgrafía desarrolló un bricolaje acéntrico, construido en ensayos metodológicos, delineados por un mapa - guión-esbozo-coreografías - que contempló la transversalización de referencias heterogéneas sobre el amor, las cuales cohabitan en la contemporaneidad y resuenan en el campo de la Educación. Como resultados, se presentan dos paisajes de amor y docencia en Facebook: ${ }^{\circledR}:$ "Bailes de 
los 15 de octubre" y "Focos de abominación a Paulo Freire". También se propone que se funden nuevas éticas amorosas llevadas a cabo como pilar de una educación para las relaciones.

Palabras clave: amor; docencia; metodología de investigación.

\title{
INTRODUÇÃO
}

\begin{abstract}
É preciso ousar, no sentido pleno da palavra, para falar de amor sem temer ser chamado de piegas, de meloso, de acientifico, senão de anti-cientifico. É preciso ousar para dizer cientificamente e não bla-bla-blantemente, que estudamos, aprendemos, ensinamos, conhecemos com o nosso corpo inteiro.

Com os sentimentos, com as emoçoes, com os desejos, com os medos, com as dúvidas, com a paixão e também, com a razão crítica. Jamais com esta, apenas. É preciso ousar para jamais dicotomizar o cognitivo, do emocional (FREIRE, 1997, p. 8-9).
\end{abstract}

A busca de metodologias que atendam aos temas, aos objetos e às finalidades de uma pesquisa acadêmica é um desafio enfrentado por muitos investigadores preocupados com o rigor e com as posturas éticas necessárias à produção do conhecimento científico. No campo das Ciências Humanas, os objetos de pesquisa, assim conhecidos devido à tradição do paradigma moderno de ciência, podem ganhar contornos maleáveis, por estarem situados em processos singulares, desdobrados em movimentos imensuráveis, que denotam constantes mudanças e geram multiplicidades. Isso torna os caminhos metodológicos abertos à imprevisibilidade dos fluxos e das linhas que dão contorno às vidas.

Essa abertura, nem sempre buscada, mas que se impõe ao processo investigativo, coloca o pesquisador em alguns dilemas, muitas vezes provocadores de perplexidades, incertezas, temores e desterritorializações, aos quais têm de enfrentar a fim de compreender o fenômeno investigado e contribuir com a elaboração e a disseminação de saberes científicos. Assim, no enfrentamento das forças vivas da pesquisa, o declínio da utilização de métodos universais e a invenção de maneiras próprias de investigar são alternativas concebidas nos percursos das virtualidades desconhecidas. O anúncio de possibilidades de criação de metodologias vem sendo feito, na contemporaneidade, por pesquisadores inscritos em chaves pós-estruturais, a exemplo de Corazza (2002), Fonseca et al. (2010), Oliveira e Paraíso (2012), Zambenedetti e Silva (2011), Zordan (2004) e outros.

Neste artigo, filiado ao campo da educação, apresento o percurso de criação de uma maneira própria de pesquisar, engendrada no âmbito de uma pesquisa de Doutorado ${ }^{1}$, realizada entre os anos de 2013 e 2017, que teve como temática a docência, entendida a partir da complexidade (MORIN, 2007) e da multirreferencialidade (ARDOINO, 1998; BORBA, 1998; FRÓES BURNHAM, 1998), e o amor, compreendido em sua multiplicidade de formas, expressas em aparências obnubilantes e modos singulares e mutantes de manifestação (ALMEIDA, 2017). Desse modo, a escolha por tratar de amor e docência visou a constituir-se em um convite, para que fiquemos atentos aos processos de expansão e de contração vibráteis do amor, que ressoam nas paisagens da educação, compreendendo-se, também, como uma possibilidade de tensionar a prática educacional, os dispositivos pedagógicos e a condição de atuação docente no Brasil, que, dispostos

\footnotetext{
${ }^{1}$ Realizada no Programa de Pós-Graduação em Educação da Universidade Federal da Bahia (UFBA).
} 
de modo complexo, em suas múltiplas referências e mecanismos, tendem a impor perfis e identidades cristalizadas à profissão.

O itinerário criativo da pesquisa, imposto pelas dobras dos territórios instáveis do amor na docência, fez-me percorrer caminhos transitórios, bem como inventar estilos, revelados em uma produção caótica, tecida em pulsações geradas por intensidades e tensões que agenciaram fluxos no intempestivo dos acontecimentos e vertigens entre sentimentos e pensamentos; pulsões de transes racioemocionais ${ }^{2}$ que deram lugar à criação. Transe, não no sentido atrelado a fenômenos religiosos e sociais de representação coletiva, ligados à iniciação em ritos ou seitas, correspondentes a determinadas divindades ou entidades, tampouco no sentido que indica um estado de alteração da consciência, marcado por reduzida sensibilidade a estímulos e pela perda ou alteração do conhecimento que se sucede à volta (HOUAISS, 2017). Ambos os significados, por extensão, apontam um estado de abstração ou de exaltação de alguém que se sente em sintonia com algo transcendente e é transportado para fora de si e do mundo sensível. Transe, aqui, se aproxima do sentido original do latim transire, ir através, ou seja, atravessar, cruzar, passar de um lugar a outro, mas também, do uso francês, no século XIII, do vocábulo transes, que indicava êxtase, extrema inquietação, temor, cuidado (HOUAISS, 2017). A conjuntura aflitiva, perigosa, os momentos críticos ou o estado de inspiração em que mergulha um artista, significados igualmente atribuídos à palavra transe (MICHAELIS, 2017), também servem para anunciar o que, aqui, indico como transe racioemocional. As inquietações e as aflições, as passagens por lugares desconhecidos e perigosos, o medo e o cuidado, os momentos críticos e o estado de inspiração são atravessamentos imanentes, que não distinguem racional de emocional, e que interferem nas escolhas de um pesquisador, ao engendrar sua pesquisa. Como coloca Bentes (1993, p. 110, grifo da autora):

O transe é transição, passagem, devir e possessão. Para entrar em crise ou em transe é preciso se deixar atravessar, possuir, por um outro. Seja uma ordem física, cósmica, a Terra, organismo biológico, organização social e política, toda ordem, estrutura ou constância será submetida, confrontada, a uma variação contínua, linha de fuga, desterritorialização.

Desse modo, abandonar as prescrições de métodos universais foi resultado de um processo de desterritorialização que sugeriu um jogo entre Ratio e Sensus, no qual não se aguarda a supremacia de um dos lados, mas um elã que implica uma dialogia entre o sedimentado e o emergente e o sentir e o pensar, como em uma conversa entusiasmada entre dionisíaco e apolíneo. Esse processo, fundado em um rigor científico outro (GALEFFI, MACEDO, PIMENTEL, 2009), denominei caosgrafia.

Por tratar-se da apresentação de um caminho investigativo singular, utilizo, no texto, um tom narrativo a fim de demonstrar os estilos desenhados por linhas que fluíram na superfície de precipitações e acontecimentos próprios de tal percurso, sem intencionar, portanto, a definição de procedimentos metodológicos passíveis de reproduções ou aplicações. No primeiro momento, trato das escolhas que potencializaram a pesquisa, discorrendo sobre a temática e suas implicações no campo da docência, além de explicitar a opção pelo Facebook $\circledR^{3}$ como campo e, ainda, destacar

\footnotetext{
${ }^{2}$ Uso o termo racioemocionais para demarcar que o sensível e o inteligível não são dimensões dissociáveis e/ou hierarquizáveis do humano e que, portanto, na produção do conhecimento científico, razão e emoção são indistintas e assumem papel relevante nas escolhas de um pesquisador ao desenvolver uma investigação.

3 Facebook é um site e serviço de rede social, lançado em 2004, operado e de propriedade privada da Facebook Inc. Para informações sobre os termos e princípios acesse https://pt-br.facebook.com/principles.php e https://ptbr.facebook.com/legal/terms.
} 
DOI: $10.12957 /$ teias.\%Y.51324

os referenciais teóricos que subsidiaram o estudo e impulsionaram o desafio de criar. Em seguida, narro as dobras da pesquisa, por meio do percurso investigativo expresso nos ensaios metodológicos realizados, que foram delineados por um mapa - esboço-roteiro-coreografias - que permitiu avistar duas paisagens de amor docente, manifestadas na referida rede social. Por fim, disserto, conceitualmente, sobre a caosgrafia, demonstrando os movimentos, as instabilidades, as desterritorializações e as reterritorializações que fizeram emergir os resultados desse processo, desdobrados na indicação de que fundemos novas éticas amorosas, esteadas em uma educação para as relações com o conhecimento, com o mundo, com o outro e consigo mesmo.

\section{SOBRE AS ESCOLHAS QUE POTENCIALIZARAM A PESQUISA}

Escolhi a temática do amor e docência porque ela tem me provocado desde o começo de minha itinerância profissional, dedicada ao campo do ensinar e do aprender no sentido complexo de experiência humana. As formas como o amor aparecia para mim, na profissão, sempre estiveram envoltas por pulsações geradas nas tensões e nas intensidades entre as permanências e as emergências do cotidiano e ressoavam, diretamente, em minhas subjetivações, o que envolvia confrontos entre imagens do pensamento, aliadas a representações fixas e a um pensamento sem imagens (DELEUZE, 1976).

Essa escolha estabeleceu-se em movimentos íntimos que envolveram, concomitantemente, Eros e Tanatus, pulsões de vida e de morte, de desejo e de negação, que promoveram tentativas de renúncia da proposta. Tal decisão não ocorreu, portanto, de modo pragmático e nem prédeterminado, mas, sim, a partir dos aconteceres e das atualizações (SÂ, 2010) de minhas subjetivações, envolvendo as multirreferências, inclusive as itinerâncias e as errâncias (MACEDO, 2000) que me compõem, sejam as de âmbito artístico, poético, ideológico, filosófico, mítico, ético, cultural, biopolítico e ainda outras, de foro íntimo e opaco, de minha constituição como pessoa que (se) educa continuamente. Assim, nas crises entre a rigidez de uma ciência, que busca a definição de uma verdade, e a flexibilidade de uma ciência, como processo de compreensão de fenômenos existenciais, permiti aceitar a fluidez de tal tema, pois, como diz Morin (1997), se o amor é união suprema da sabedoria e da loucura, temos de assumi-lo.

Além disso, o assunto amor na docência é pauta recorrente entre professores no Facebookß. Como usuária dessa rede social, fui arrastada pelo seu campo de potência ao ser afetada pela intensidade de postagens de docentes, expressando as inúmeras formas que concebem o amor, em relação ao seu trabalho. Essas manifestações serviram para o encontro de corpos vibráteis, produto das relações de forças e de multiplicidades (ULPIANO, 1989), e confirmaram que esse é um assunto caro a muitos outros professores. Diante dos "barulhos" que me invadiam ao observar/participar das postagens, fiz uma segunda escolha: a do Facebook ${ }^{\circledR}$ como campo de

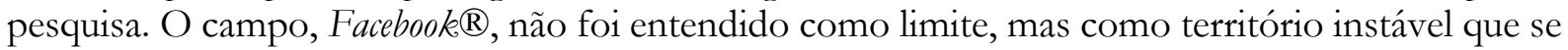
lança em vários planos, que estabelece diversas zonas de vizinhança e que, na sua interface espacial virtualizante, produz atualizações (GALEFFI, SALES, 2012). Ele serve como instrumento-palco onde ocorrem múltiplas conexões, em variados domínios, nas quais eclodem expressões de como construímos o mundo; por isso, um campo que é descamado, mas que se regenera e se descama, continuamente, multiplicando-se em inúmeras estratificações.

A desconfiança de que, ao tratar de amor e docência, não poderia partir de um discurso monológico e homogeneizante, me levou a fazer, também, a escolha pela manutenção de referenciais, os quais eu já havia encontrado em meus percursos formativos: a complexidade (MORIN, 2007) e a multirreferencialidade (ARDOINO, 1998; BORBA, 1998; FRÓES 
BURNHAM, 1998). A complexidade entende que os tecidos dos acontecimentos é feito de ações, interações, retroações, determinações e acasos. Ela nos aproxima do duvidoso, do vacilante, das ambiguidades, dos assombros e dos emaranhados que nos constituem em nossa humanidade; articula duplos como ordem e desordem, separação e união, autonomia e dependência, envolvendo-os em suas possíveis complementaridades e ambiguidades. O pensamento complexo "[...] é capaz de contextualizar e globalizar, mas pode, ao mesmo tempo, reconhecer o que é singular e concreto" (MORIN, 2007, p. 76). A multirreferencialidade segue nessa linha e abarca a pluralidade, o multilógico e a heterogeneidade, concebendo traços inquietantes da confusão, do inextricável, da desordem no caos e da incerteza diante das múltiplas referências de compreensão do mundo (FRÓES BURNHAM, 1998). Ela “[...] exige ou comporta uma bricolagem, ou, em outras palavras, uma abordagem a partir de perspectivas múltiplas” (BORBA, 1998, p. 18) e se faz como um luto de unidade (ARDOINO, 1998). Assim, os princípios epistemológicos da complexidade e da multirreferencialidade alicerçaram o estudo em oposição à busca da "verdade universal" aspirada pelo pensamento disjuntor, dogmático e instrumental da ciência moderna. Tais referenciais foram, por conseguinte, acionados em contraposição a um pensamento higienista, linear, ortodoxo e totalizante, já que tratam de fluxos, de incompletudes, de imperfeições e de desordens, imbuídas "[...] simultaneamente de verdades e não verdades" (MORIN, 2007, p. 97) e que "[...] não se curvam a reducionismos" (BORBA, 1998, p. 13).

Percorrendo outros caminhos, mas ainda me situando na crítica à imagem dogmática do pensamento que, em busca da verdade, alude à ideia de que o sensível, como força estranha do pensamento, nos conduziria ao erro, assim como a indicação de que é necessário um método que nos faça pensar verdadeiramente (DELEUZE, 1976), me recusei a aceitar, passivamente, a indicação de um método definido a priori e procurei uma tecnologia da justificação (KINCHELOE, BERRY, 2007) que defendesse, de alguma forma, o processo pelo qual fui elaborando a maneira de pesquisar que resultou na tese. Nessa busca, encontrei-me com o conceito de bricolagem de Claude Lévi-Strauss (1976), trabalhado, posteriormente, por Joe Lyons Kincheloe e Kathlenn Berry (2007), e com alguns conceitos da geofilosofia de Deleuze (1976, 1992, 1997), Deleuze e Guattari (1995a, 1995b, 1997, 2012) e Deleuze e Parnet (1997). A escolha desse referencial contribuiu com o exercício do pensamento, ou seja, com a possibilidade de elaboração de novos modos de pensar, para além dos discursos binários e de representações fixas.

A bricolagem e a geofilosofia ofertaram à pesquisa um caráter heteróclito e a abertura necessária a sentirpensar os amores em suas composições eternamente (re)criativas e complexas. Serviram para evidenciar as tensões entre a vinculação de uma forma de amor a uma representação fixa e a emergência de novas formas, propondo a diferença como mote, para favorecer outras expressões do pensamento. $\mathrm{Na}$ itinerância da pesquisa, foram se constituindo como planos de especulação que agenciaram processos de territorialização, desterritorialização e produção de novos territórios, nos quais as conexões e a heterogeneidade foram forças latentes. O diálogo com essas posturas teórico-epistemológicas permitiu a enunciação do caráter polimorfo do amor, em algumas de suas múltiplas aparências e maneiras singulares e mutantes de manifestação e que compõem paisagens transitórias na docência.

Mergulhada nessas referências, o exercício de sentirpensar sobre as relações entre a minha singularidade, meus processos de subjetivação e as singularidades e as subjetivações de outros professores, no que tange ao amor na docência, não ocorreu a partir de uma lógica de ordenação

\footnotetext{
${ }^{4}$ Especificamente, os conceitos de subjetivação, de agenciamento, de território, de rizoma, de mapa, de decalque, de segmentarização molar e molecular e linhas de fuga.
} 
hierárquica, com entrada e saída, mas sucedida no caos e no transbordamento dos aconteceres. Ele foi sendo atravessado, intermitentemente, pelos encontros entre fluxos de permanência e fluxos de emergência.

Os fluxos de permanência indicam os saberes e crenças secularmente construídos que povoam os atravessamentos históricos, mas que não são cristalizados e nem desconectados da contemporaneidade; os fluxos de emergência referem-se aos novos saberes e crenças que surgem aliados às permanências históricas. Ambos coexistem nas temporalidades humanas, em uma dialógica processual de atualizações, potencializações, virtualizações, homogeneizações, heterogeneizações. (ALMEIDA, 2017, p. 23).

$\mathrm{Na}$ latência da pesquisa, os movimentos do encontro de tais fluxos sinalizaram a impossibilidade de existência de um mundo a priori, um solo firme e independente a ser consumido e reproduzido e, desse modo, estático e intacto, quiçá não passível aos afetos. Eles demonstraram a intempestividade dos acontecimentos, das precipitações e dos encontros entre linhas molares e moleculares (DELEUZE, GUATTARI, 2012); assim, abriram o estudo ao caos e às conexões. Esse cenário instável impôs-se e arrastou-me para transes racioemocionais, nos quais fui atravessada por permanências dos saberes de amor, advindos das multirreferências científicas, artísticas, filosóficas e culturais, pelas emergências do conturbado contexto sociopolítico brasileiro e pelas ressonâncias desses fluxos na docência. Imersa nesse cenário fiz mais uma escolha: a de criar.

\section{DOS ENSAIOS METODOLÓGICOS: ROTEIRO, ESBOÇO E COREOGRAFIAS, NENHUM E TODOS ELES, NAS DOBRAS DA PESQUISA}

Ao criar, humildemente, um estilo, que nasceu de encontros que agenciaram uma maneira própria de pesquisar, tentei fazer um exercício nômade de pensamento, no que se refere a uma possibilidade de elaboração de outras formas de conceber o mundo, formas que privilegiem a "[...] intensidade em detrimento das representações" (PELBART, 1993, p. 61). No âmbito da pesquisa, as pulsações da vivência no Facebook ${ }^{\circledR}$ iniciaram-se no estranhamento e na suspeita quanto aos consensos e às ideias partilhadas, aos quais estamos acostumados, quando o assunto é amor. Em meus transes racioemocionais, ao assumir uma maneira própria de pesquisar, que não seguiu a aplicação mecânica de um arsenal metodológico, pautado em estratégias ossificadas, estive à procura de pistas, de lances e de fissuras nas rotas desenhadas, tanto por mim como pelos docentes em suas manifestações na referida rede social. Com isso, experimentei um inusitado espaço de liberdade que foi emergindo nos devires das dobras da pesquisa. Nas itinerâncias e nas errâncias (MACEDO, 2000) das escolhas que fui fazendo, o rigor fez-se como tensionamento justo (GALEFFI, 2009) e impulsionou-me a uma guerrilha de suspeição (CORAZZA, 2002), fazendo com que eu submetesse as minhas opções a confrontos continuados e a inúmeros retornos, necessários para manter o dom da dúvida.

As paisagens apresentadas na tese foram sendo constituídas a partir do estranhamento do real, da exploração de potências, de tensionamentos, de deslocamentos territoriais e dos encontros entre fluxos de permanência e de emergência. Foram tecidas em um jogo entre as relações de poder que impregnam as concepções de amor que ressoam no ideário da docência e as múltiplas formas que professores elegem para manifestá-las. As expansões e as contrações vibráteis desse jogo fizeram com que eu escrevesse e desistisse de roteiros, desenhasse e apagasse esboços e criasse coreografias, com diferentes sons. Elas me levaram a realizar ensaios metodológicos na tentativa 
DOI: $10.12957 /$ teias.\%Y.51324

de suspender minhas verdades e questionar crenças antigas. Na aventura desses ensaios, nem sempre bem-sucedidos, cartografei vibrações que compõem paisagens transitórias da docência, nas quais o amor transita e das quais eu faço parte.

\section{O roteiro}

No primeiro ensaio metodológico, escrevi um roteiro imaginando que seria possível mensurar, controlar e guardar em um lugar, facilmente acionável, as manifestações de professores sobre o amor em sua profissão. Acreditando transitar em um território estável, inspirei-me no cantor e compositor brasileiro Geraldo Vandré e abri, no Facebook ${ }^{\circledR}$, um grupo denominado Para não dizer que não falei das flores, de amor e de professores. Divulguei-o, ao máximo, entre meus Facefriends ${ }^{5}$ e disseminei o link em vários outros grupos, relativos à docência. Com isso, consegui agrupar, em um intervalo de uma semana, 690 professores interessados em participar. Com esse resultado tão rápido, a ilusão do controle seduziu-me. Criei um grupo fechado; desse modo, as pessoas precisariam da minha aprovação para entrar, e o seu conteúdo só seria partilhado entre os integrantes; inclusive, fiz questão de deixar isso em evidência, na postagem fixa que apresentava a página do grupo. Nessa mesma postagem, anunciei que se tratava de um levantamento inicial do contexto do tema amor e docência para minha pesquisa de doutoramento, determinei uma série de regras e deixei demarcado que apenas professores da educação básica estavam convidados, categorizando os integrantes e segregando, de algum modo, as pessoas aptas ou não aptas a dialogarem sobre amor e docência naquele espaço.

Durante algum tempo, o grupo foi bem movimentado com postagens, comentários e interações sobre o assunto, porém, gradativamente, a intensidade das participações foi diminuindo, o que serviu como um acionador de risco, que agenciou uma dobra e que fez com que eu tentasse assumir, ainda mais, a direção do roteiro. Passei a atuar no enredo fazendo postagens e provocando discussões sobre o tema; com isso, consegui com que a "audiência" se reestabelecesse. Quando comecei a acreditar que, finalmente, o clímax do enredo tinha contagiado os "espectadores" e que conseguiria coletar o material para a pesquisa, a trama se mostrou desinteressante. Percebi muitos pudores em relação a discordâncias, contestações, negações, do mesmo modo, em relação a assertivas, demonstração de crenças e disposição para o diálogo.

Com quase nenhuma intensidade e, praticamente, sem qualquer te(n)são, o roteiro, que parecia ser de uma trama perfeita, não demonstrou ser um espaço de passagem. Por ignorar que os movimentos das subjetividades são nômades (FONSECA et al., 2010), fiz dele um espaço inócuo. Não havia compreendido, ainda, que “[...] a 'coleta de dados' só pode ser operada no encontro entre o pesquisador, suas ferramentas conceituais e o campo, encontro esse que pode modificar tanto o pesquisador quanto apontar os caminhos possíveis para a constituição de um campo" (ZAMBENEDETTI, SILVA, 2011, p. 455). O grupo não foi deliberadamente rejeitado, até porque, apesar de ser o decalque (DELEUZE, GUATTARI, 1995a) de um namoro morno, como aqueles vigiados pelos pais, o número de solicitações de entrada, a adesão rápida e as interações ocorridas anunciaram que o tema era caro para muitos docentes que aderiam ao Facebook®. Além disso, foi partindo dele que me reconheci no meu primeiro transe raciomemocional e me estranhei no fazer da pesquisa; foi, nele, que fluxos me atravessaram e fizeram com que me sentisse incomodada e insatisfeita com o percurso traçado; e foi, na fraqueza dele, que outras forças puderam eclodir.

\footnotetext{
${ }^{5}$ Nome dado aos amigos que integram o perfil de um usuário do Facebook®.
} 
DOI: $10.12957 /$ teias.\%Y.51324

Ele produziu marcas que agenciaram desterritorializações e reterritorializações (DELEUZE, GUAT'TARI, 1995a) no devir tese.

O esboço

Resolvi abandonar o roteiro e iniciei um segundo ensaio metodológico: o desenho de um esboço. Embora com a experiência do roteiro já soubesse que não seria possível partir de um único ponto, ainda almejava chegar a ele. O desenho foi esboçado como uma representação molar, com uma lógica binária, em um terreno estriado como se almejasse chegar ao topo de uma árvore (DELEUZE, GUATTARI, 1995b). A ilusão do controle ainda me seduzia ao ponto de continuar acreditando que seria possível delimitar, na rede social, os ambientes em que os amores de docentes poderiam ser anunciados.

Para desenhar o esboço, usei a ferramenta de busca do Facebook® e conjuguei a palavra amor com as palavras professor, professora, docência, escola, educação e ensinar. Em 2015, encontrei 37 grupos que, pelos seus nomes ou nas suas descrições, designavam, como intenção, tratar de amor e docência/educação. Alguns grupos eram fechados, assim como possuíam regras explícitas, ou não. Eram povoados predominantemente por mulheres, o número de integrantes variava entre seis e 98 mil e os locais onde os(as) participantes viviam, apesar de variados, eram todos em território brasileiro. Com essa variedade de possibilidades, acreditei que, enfim, encontraria um destino. Contida, porque não me sentia mais a diretora de um roteiro, inicialmente, me coloquei como uma observadora.

As interações disparadas por postagens, comentários e memes me atravessaram com diferentes graduações de intensidade. Tais graduações compuseram "[...] escalas de observação, análise e operação no desenvolver da pesquisa” (FONSECA et al., 2010, p. 173). As escalas de menor intensidade referiam-se ao fato de que eu esperava que houvesse um debate sobre amor e docência nos grupos, mas isso não aconteceu. Ao contrário do roteiro do grupo criado por mim, que determinava o assunto a ser tratado, nesses outros grupos, os(as) docentes não estavam, necessariamente, interessados(as) em dizer de seus amores. Os assuntos eram os mais diversos, embora sempre relativos à educação.

Nas manifestações de docentes nesses espaços, não percebi, inicialmente, que o amor, apesar de não ser o conteúdo, era assunto e estava expresso de múltiplas formas. As intensidades e as tensões existiam, mas eu ainda não havia me permitido ir ao encontro dos corpos vibráteis (RONILK, 1993). Depois de algum tempo, inconformada com a minha (pseudo)passividade e sedenta pela busca do objeto, não me satisfiz com os pequenos prazeres que a observação me causava. Não havia me dado conta que esse meu, terrível, comportamento animal de "[...] ser à espreita, um ser fundamentalmente à espreita" (DELEUZE, PARNET, 1997, p. 5), já era um anúncio de como as paisagens de amor e docência estavam agenciando a construção de um estado de presença, na minha postura como pesquisadora.

A observação, aos poucos, foi dando lugar ao encontro de corpos vibráteis e me apresentei nos grupos como uma participante assídua. Contudo, minhas manifestações eram sempre diretivas e impetuosas: não havia aprendido, ainda, com os dramas que vivi no roteiro que criei, que impor um diálogo sobre as aparências obnubilantes do amor não seria profícuo e nem coerente com o referencial que estudava e que começa a provocar atualizações na maneira com que eu concebia a pesquisa. Questionava os(as) professores(as) sobre o que expressavam e relacionava, às vezes até de modo forjado, os posts e comentários ao amor. Era como se eu estivesse aplicando um questionário objetivo-indutivo e aguardando as respostas adequadas para seguir no caminho que 
tracei no esboço. Além disso, estava menosprezando o Facebookß, tentando delimitar suas conexões, barrar seus fluxos e reduzi-lo a, apenas, um mero instrumento.

Com a pretensão de recortar um segmento do mundo, empreendi atos de dominação (FONSECA et al., 2010) que inibiram as manifestações livres. Provoquei desconfiança sobre os meus propósitos e isso fez com que eu desconfiasse de mim mesma, pois a intensidade dos silêncios se sobrepôs aos sussurros que consegui ouvir. Ao ampliar o olhar sobre os movimentos da subjetivação, me dobrei e experimentei a mim mesma, me lançando ao desafio de alterar as formas de intervir (FONSECA et al., 2010). As linhas retas, do velhonovo esboço, tinham sido cortadas por outras linhas; linhas moleculares, desobedientes e selvagens, que não se curvaram ao desenho feito e rabiscaram os contornos dos traçados. O roteiro e o esboço molares foram apagados, mas não por completo, já que as linhas moleculares não são entidades. Elas coexistem com as linhas molares, segmentando os acontecimentos.

As vibrações das linhas, que agenciam os encontros dos corpos, provocaram-me a sentir as intensidades de maior escala dos grupos. Elas me atravessaram e potencializaram transes racioemocionais que me fizeram sentirpensar, ao ponto de me transportarem para o entorno dos grupos; para aquilo que poderia ser o detonador dos desejos de docentes ao se presentificarem nas virtualizações e nas atualizações daqueles territórios. Tais intensidades me fizeram declinar das tentativas de provocar professores(as) a falarem de seus amores, apenas porque participavam daqueles grupos. Comecei a perceber que, nas interações, nem sempre dialogadas, era exposto “[...] o percurso das forças, as séries com as quais se conectam, as relações de vizinhança que estabelecem, os modos pelos quais se agrupam, se associam entre si e dissociam seus elementos" (ZORDAN, 2004, p. 16).

$\mathrm{Na}$ perplexidade da ausência de um objeto puro, encontrei a hibridez de suas formas nas zonas de vizinhança (DELEUZE, GUATTARI, 2012) que professores(as) estabeleciam com as suas múltiplas referências de mundo e as condições sociopolíticas da profissão docente no Brasil. O que estava em jogo não eram, necessariamente, as palavras de amor expostas, mas manifestações mais densas, que elaboravam as experiências situadas, contextualmente, naquele território. Ali estavam as pistas das múltiplas linhas que desenham as paisagens de amor e docência no Facebook®.

A partir de algumas tensões, não exclusivamente, entre os membros dos grupos, alguns fluxos emergiram (d)nas permanências e, nesses encontros, velhasvelhas, novasvelhas e novasnovas paisagens, sempre provisórias, foram sendo engendradas. Nessa conjectura, o esboço mostrou-se improdutivo, pois voltava sempre ao mesmo, também, como um decalque (DELEUZE, GUATTARI, 1995a). Os enredamentos dos fluxos eram lançados, constantemente, no Facebook® e serviram de sinais para que eu apostasse na desenvoltura do olhar e percebesse que o amor era, ali, anunciado, mesmo que tacitamente. Percebi que não era mais preciso "gritar para ouvir sussurros", pois muitos eram os "barulhos" que pululavam nos grupos e para além deles. Tais sons me deslocaram do dentro e me fizeram atentar para o movimento do entre, para as dobras do dentro e dos foras; assim, os amores docentes não estão descritos, linearmente, em um ou mais grupos, mas, sim, na interface espacial virtual/atual do Facebook®, em sua amplitude. Os amores são manifestados nas relações de vizinhança que docentes estabelecem com os inúmeros agenciamentos que atravessam a profissão. Não seria dentro de um território que encontraria um território, mas, sim, nos entres de múltiplos territórios.

O atravessamento de fluxos de permanência e de emergência possui barulhos ensurdecedores, que produzem novos e múltiplos agenciamentos, incessantemente. É rizoma que estabelece "[...] conexões transversais sem que se possa centrá-lo ou cercá-lo" (GUATTARI, RONILK, 2010, p. 322), pois, nele, coexistem escalas de tensão e de intensidades múltiplas. Nos 
ensaios metodológicos do roteiro e do esboço, prévios, percebi que não era possível enclausurar as potências e as forças vivas, que se expressavam nos encontros dos corpos, incluindo o meu próprio. Entretanto, os abandonos servis já não eram mais possíveis e tive de inventar meios de conviver com o que parecia estável, mas que, na verdade, era puro movimento. O território escamado do Facebook ${ }^{\circledR}$, na amplitude de seu espaço e com seus fluxos inestancáveis, agenciou outras possibilidades de encontros entre amor e docência. Ele me solicitou a reconhecer e explorar os modos diversos de como são produzidas subjetivações, para além das barreiras/fronteiras dos grupos. Desse modo, abandonei os terrenos cercados e aderi às manifestações livres.

\section{As coreografias}

O Facebook® é afetado, diretamente, pelos fluxos dos acontecimentos e produz encontros, de planos vivos, que agenciam a criação de novas paisagens. Dois encontros que me invadiram, contribuíram para as dobras da pesquisa e engendraram a criação das paisagens de amor e docência, foram os que denominei de Bailes dos 15 de outubro e Focos de abominação a Paulo Freire. Esses eventos foram as linhas bailarinas (OLIVEIRA, PARAÍSO, 2012) que impulsionaram um novo ensaio metodológico: uma coreografia des(com)passada. Coreografia, ore(o)- + -grafia, escrever-com, envolve a arte de conceber movimentos e passos que vêm a compor uma dança (HOUAISS, 2017). Para compor passos, não apenas reproduzi-los, é preciso sentir a intensidade do ritmo, mover o corpo, vibrar. É muito mais o som que leva o bailarino a dançar do que a técnica; por isso, chamei os passos, desse movimento da pesquisa, de uma coreografia des(com)passada. Des-passada, pois, além dos passos não terem sido definidos, a priori, eles se fizeram em retornos, com oposições, negações, separações; com-passada, pois foi sendo composta com os barulhos dos atravessamentos dos fluxos que me fizeram bailar em uma bricolagem subvertedora de homogeneizações. $\mathrm{Na}$ medida em que aceitei a infinidade pulsante dos acontecimentos, fui criando passos, que se transformaram em um "[...] atrator de virtualidades que pedem passagem" (FONSECA et al., 2010, p. 176).

A paisagem engendrada nos Bailes dos 15 de outubro refere-se à passagem do Dia dos Professores no Brasil. Durante os quatro anos da pesquisa, especialmente nesses dias, observei inúmeras manifestações de amor de docentes. Os picos de intensidade foram os sinais que provocaram a criação dos primeiros passos do mapa dançante da pesquisa. Os "gritos e suspiros" apareciam na minha timeline em um ritmo frenético, advindos de várias instâncias, com intenções e lógicas muito distintas. Quando passei a dançar, nessas linhas bailarinas, compreendi que não conseguiria compor passos harmonizados com o ritmo dos sons. Como não era possível aguardar repetições previsíveis, seriam os despassos que criariam os compassos da dança.

As formas de amor, expressas nesses sons, impuseram a visibilidade das aparências que tal sentimento pode assumir; algumas, inclusive, que eu já conhecia em minha itinerância como docente: missão, sacerdócio, maternidade, ato político, vocação, dom. Essas são as aparências que o amor assume na docência, com maior intensidade, porém, nos 15 de outubro, elas praticamente se tornam entidades e se cristalizam em identificações amorosas irrefutáveis. Essa tendência ao enrijecimento não parte somente de docentes. Há uma relação de poder velada em tais representações, que se manifesta em um jogo perverso, cujas peças são envoltas por finalidades escusas. O fim comercial desses discursos é notável. Muitas instituições, sejam elas públicas, do terceiro setor ou com fins lucrativos, "vendem" o amor à docência. Pela intensidade da participação de professores nos perfis desses estabelecimentos, percebe-se que eles se identificam com as concepções de amor postas.

Concomitantemente aos Bailes dos 15 de outubro, captei outros ruídos muito intensos; tão fortes que, mesmo que eu estivesse desatenta, não seria possível ignorá-los. Estou me referindo à 
composição dos passos mais dramáticos das coreografias, aqueles que me provocaram, muitas vezes, a pensar em desistir de bailar com o amor: coreografar ao som dos urros que as lanças do medo e do ódio emitem, até o alcance de seus alvos.

Desde 2013, ano em que a pesquisa começou a ser desenvolvida, é possível notar que o Brasil sofre uma série de atentados contra a democracia, advindos de muitas esferas, coligadas ou não, com diferentes naturezas e modos de operação variados. Em uma sombra, similar as de alguns regimes totalitários, as lanças do medo e do ódio que são atiradas por/sobre nós, vêm alvejando e enfraquecendo, paulatinamente, a manifestação de emoções que nos fazem seres de

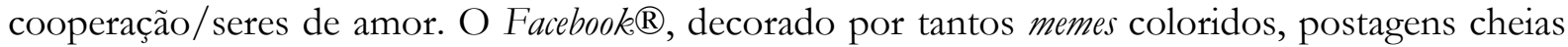
de flores e de emojis com coraçõezinhos, muito comuns, nos 15 de outubro, passou a receber, também, de modo transversalizado, excessivas postagens de ódio. Diante desse contexto, no que tange amor e docência, é de esperar-se que o alvo não seja voltado para as aparências de amor como missão, maternidade e outras similares; o alvo é específico: o amor da pedagogia freireana. Especialmente, depois de 2016, Paulo Freire e suas teorizações começaram a ser abominados no Brasil, e isso passou a ter ampla repercussão no Facebook®. Os posts sobre o amor da Pedagogia Libertadora, mesmo quando não possuem qualquer conotação política e, até mesmo, quando têm finalidades comerciais, passaram a receber uma enxurrada de comentários, muitas vezes, descontextualizados e vazios de argumentações, classificando o amor político de Paulo Freire, como doutrinação ideológica. As postagens de amor e ódio em relação a Paulo Freire estavam, ali, nas fendas do Facebook ${ }^{\circledR}$, coexistindo, indistintamente, com o mundo cor de rosa das heroínas e dos heróis missionários dos 15 de outubro.

Mesmo sem conceber essa perspectiva mais ampla no começo da pesquisa, desde quando ensaiava, por meio de um roteiro e de um esboço, não me colocava à disposição de analisar, interpretar, dizer pelos professores, o que eles haviam dito. Ao ler, cortar e colar os posts e comentários utilizados na pesquisa, não me propus a analisar os discursos e nem fazer uma ligação biunívoca do que estava escrito com as formas de amor que permanecem em nosso imaginário social. Em se tratando de amor e docência e de amor e docência no Facebook®, o que poderia ser engendrado, eram apenas curvas de visibilidade e enunciação de paisagens, pois o amor, como força pungente da vida, não comporta a leviandade das regulações de análises e de interpretações. Ele eclode, rompendo com as estabilidades e impondo a defasagem, continuada, dos limites.

\section{A CAOSGRAFIA}

Escrever/com-caos: viver um processo de expansão de contração pulsátil, que agencia o intempestivo dos acontecimentos e as vertigens entre os sentimentos, os pensamentos e a invenção.

Escrever/com-caos: dançar entre as linhas bailarinas, sem evitar os choques e sentir a pulsação dos barulhos, oriundos dos encontros de fluxos de permanência e de emergência, deixando que eles brotem, sem ter a dimensão de suas ressonâncias.

Como desejava acompanhar um processo e não representar um objeto (KASTRUP, 2007), meus movimentos, mesmo os iniciais, já eram coreografias des(com)passadas. Eles começaram a partir de um roteiro, escrito em uma linha delimitada e reta, que se estirou e se tornou mais flexível, no desenho do esboço e, ao encontrar-se com inúmeras outras linhas, arredias, abriu-se no baile do rizoma. Escrever um roteiro e desenhar um esboço demandam criação. Mesmo sendo um mapa dirigido ou um mapa contornável - decalques - envolvem, de algum modo, um esforço inventivo e uma força de produção, que não são antagônicas a um mapa dançante. Apesar dos decalques tenderem à estatização dos movimentos, eles não são imunes às vibrações do real. O que distingue 
o decalque do mapa é que, este último, está voltado para uma experimentação ancorada no real (DELEUZE, GUATTARI, 1995b). Nos transes racioemocionais que vivenciei e nas paisagens que habitei, o roteiro e o esboço já eram, portanto, coreografias, pois as linhas bailarinas já estavam, potencialmente, presentes no emaranhado-rizoma. Neles, sucessiva e simultaneamente, ora experimentei o caos, em busca de fixar-me em um centro, vivi um infra-agenciamento; ora tive a sensação de estar estável em um território, uma espécie de em-casa e vivi um intra-agenciamento; e ora escapei do em-casa, pedindo passagem para as fugas (DELEUZE, GUATTARI, 1997). Apesar das paradas, motivadas de dentro e em função do trajeto, essas forças me afrontaram e atualizaram os mapas que geraram os arranjos para as performances dos des(com)passos.

O mapa criado no roteiro-esboço-coreografias permitiu-me uma razoável visão dos territórios que eu estava bricolando. As paisagens bricoladas que foram apresentadas, na tese, não foram apenas compostas por elementos que capturei e colei, artesanalmente, montando fragmentos de amor, que ressoam na docência e que são advindos dos encontros entre fluxos de permanência e de emergência. Elas foram aparecendo, para mim, nos transes "[...] delirantes que ultrapassam as divisões entre o entendimento(razão), o sentimento(afetos) e a sensação(empírico)" (FONSECA et al., 2010, p. 170).

Desse modo, tais paisagens foram compostas, também, por movimentos, instabilidades, desterritorializações e reterritorializações, já que os fluxos, os movimentos e as circunstâncias deram forma ao método, assim como permitiram a abertura ao diálogo com discursos conflitantes, sem delimitar fronteiras ou predomínio de um sobre os outros (KINCHELOE, BERRY, 2007). Os movimentos acêntricos, rizomáticos, dos atravessamentos que sofri - as dobras que empreendi - revelaram que a bricolagem estava sendo feita, pois havia a intercepção das forças das relações de poder que, veladas, encobrem a docência e que, explícitas, disseminam o ódio que afeta algumas ideias de amor e educação. Por isso, a bricolagem constituiu-se nos encontros: na criação de redes entre conceitos e acontecimentos e no cruzamento das estratégias flexíveis da feitura de um método.

Esse esforço ficou evidente nas coreografias des(com)passadas, talvez des-pensadas ou compensadas, mas sempre sentidas: abertas, plurais e ramificadas em possibilidades intangíveis. O mapa roteiro-esboco-coreografias é o próprio rizoma da pesquisa, que permitiu a bricolagem de inúmeras referências, sem homogeneizá-las. Esse exercício de criação demandou uma atitude investigativa sensível à diversidade de formas que acompanham as concepções de amor de professores, atitude que me convocou a associar e desassociar contextos, alinhavar referências, cruzar permanências e aceitar emergências. Foi preciso enredar fluxos, tramar saberes e crenças, cortar e costurar posts, colar e rasgar comentários; bricolar, assim, a enunciação de sentidos, fazendo combinações e montagens, dando visibilidade a tensões, permitindo a graduação de intensidades, sem sobrepor ou privilegiar referências. Com isso, tentei afastar-me de dicotomias ou privilégios que pudessem marginalizar e discriminar as concepções de professores sobre o amor na profissão. Foi a partir dessa postura racioemocional que pude avistar algumas paisagens nas linhas, nas operações, nos arranjos, nos dispositivos, nos agenciamentos e nas redobras sobre como o amor era expresso, por professores(as), no Facebook®, e foi, na imersão das próprias paisagens, que montei os cenários bricolados com os posts que estão dispostos na tese.

Nessas paisagens, transitórias, roteiro, esboço e coreografias, em efervescência, agenciaram as dobras da pesquisa - caosgrafia: movimentos em torno das tensões e das intensidades entre a rebeldia e a ordem, compostos por linhas de múltiplas naturezas, zonas de vizinhança, pontos limites e permanentes ultrapassagens, que produzem o infinito e fazem com que a dobradura do real se instaure plena de novidade (FONSECA et al., 2010). No plano caótico do Facebook®, para 
ir ao encontro de corpos vibráteis, precisei combinar “[...] elementos heterogêneos, díspares, fazendo surgir algo de novo, que não se pode reduzir a nenhum dos elementos isolados que o compõem" (SILVA, 2004, p. 157). Por isso, não me ative a fazer acordos e correspondências; precisei me envolver com as linhas bailarinas para encontrar um lugar no qual o ver e o dizer estivessem entrelaçados, na produção de sentidos e se mantivessem, mutuamente, irredutíveis (DELEUZE, 1992). Ao assumir uma postura acêntrica, complexa e multirreferencial, busquei afirmar que as permanências e as emergências, em suas múltiplas linguagens, não podem ser desprezadas, igualmente não podem ser evidenciadas como forças prioritárias e hierárquicas.

Ao bricolar os encontros: entre as referências teóricas, aproximando-as e distanciando-as; entre as referências das artes, da literatura, do cinema, dos mitos, dos ditos populares... quanto ao amor; e entre as emergências do conturbado contexto sociopolítico brasileiro, um estilo de pesquisar foi sendo tecido. Escrever/com-caos: caosgrafia brotou da enunciação de inferências e contextos sociais, de elaborações culturais, das dimensões sociopolíticas, da apreciação estética, dos conceitos filosóficos e das relações de poder que recobrem as formas de amor na docência, sem desprezar o que é tido como ciência, daquilo que se constrói como ciência. Nasceu em um fazer manipulado no encontro de corpos e que é politicamente situado: amores docentes; nasceu nos atravessamentos dos fluxos de mundo, tendo em vista a força imanente que é a própria vida.

Desse modo, a caosgrafia tendeu a corresponder a uma vitalidade existencial quando bricolou afetos, indagações, certezas movediças, tensões, fluxos. Quando, também, mais do que dobrar a pesquisa ao tratar de amor de professores(as), fez com que eu me dobrasse sobre mim mesma e sobre as minhas maneiras de amar. Essa cinesia agenciou as dobras que fiz com a/na pesquisa na sintonia entre o sensível e o inteligível, pois, quando ao me permitir ser afetada por transes racioemocionais, o real pôde se expandir. Nas minhas dobras com a pesquisa, fui engendrando uma postura de questionamento das relações de poder que utilizam discursos pró-amor e contra amor, para incutir a definição de perfis e de identidades cristalizadas aos(às) professores(as), na tentativa de puxar algumas linhas que pudessem começar a desmanchar alguns territórios rígidos, nos quais eu, também, habito.

Os bailes da caosgrafia agenciaram alguns encontros entre afetações molares e moleculares, fluxos de significação, barulhos ensurdecedores, silêncio sepulcral, latências e potências singulares e as relações de poder. No movimento de suas dobras, ela sugeriu, ainda, que fundemos novas éticas amorosas, que se desenvolvam no esteio de uma educação para as relações: relações com o conhecimento, com o mundo, com o outro e consigo mesmo. Com isso, evidenciou a vitalidade do amor encarnado, mundano e plural, com a intenção de dizer sim à vida, a uma vida (DELEUZE, 1997). A caosgrafia anunciou que, na dança das dobraduras do nosso visível, existem pulsações que promovem os encontros que geram, ininterruptamente, novas formas de amor.

\section{REFERÊNCIAS}

ALMEIDA, Verônica Domingues. poli[AMOR]fia: paisagens da docência. 2017. Tese (Doutorado em Educação), Universidade Federal da Bahia, Salvador, 2017. Disponível em https://repositorio.ufba.br/ri/handle/ri/24776. Acesso em 1 set. 2020.

ARDOINO, Jacques. Abordagem multirreferencial (plural) das situações educativas e formativas. In: BARBOSA, Joaquim. (coord.). Multirreferencialidade nas ciências sociais e na educação. São Carlos: Ed. da UFSCar, 1998. p. 24-41.

BENTES, Ivana. Transe, crença e povo. Cadernos de Subjetividade, São Paulo, v. 1, n. 1, p. 109-120, 1993. 
BORBA, Sérgio. Aspectos do conceito de multirreferencialidade nas ciências e nos espaços de formação. In: BARBOSA, Joaquim. (org.). Reflexões em torno da abordagem multirreferencial. São Carlos: EDUFSCAR, 1998. p. 35-55.

CORAZZA, Sandra Mara. Labirintos da pesquisa, diante dos ferrolhos. In: VORRABER, Marisa. (org.). Caminhos investigativos: novos olhares na pesquisa em educação. 2. ed. Rio de Janeiro: DP\&A, 2002. p. 105-131.

DELEUZE, Gilles. Nietzsche a e filosofia. Tradução Ruth Joffily e Edmundo Fernandes Dias. Rio de Janeiro: Editora Rio, 1976.

DELEUZE, Gilles. Conversações. São Paulo: Editora 34, 1992.

DELEUZE, Gilles. A imanência: uma vida. In: VASCONCELOS, J.; ROCHA F. A. (org.). Gilles Deleuze: Imagens de um filósofo da imanência. Londrina. Ed. UEL, 1997. p. 15-19.

DELEUZE, Gilles; GUATTARI, Félix. Mil Platôs. Vol. 1. Tradução Ana Lucia de Oliveira, Aurélio Guerra Neto e Célia Pinto Costa. São Paulo: Ed. 34, 1995a.

DELEUZE, Gilles; GUATTARI, Félix. Mil Platôs: capitalismo e esquizofrenia Vol. 2. Tradução Ana Lúcia de Oliveira e Lúcia Cláudia Leão. São Paulo: Ed. 34, 1995b.

DELEUZE, Gilles; GUATTARI, Félix. Mil Platôs: capitalismo e esquizofrenia. Vol. 3. Tradução Ana Lucia de Oliveira, Aurélio Guerra Neto, Lúcia Cláudio Leão e Suely Ronilk. 2. ed. São Paulo: Ed. 34, 2012.

DELEUZE, Gilles; GUATTARI, Félix. Mil Platôs: capitalismo e esquizofrenia. Vol. 4. Tradução Suely Rolnik. São Paulo: Ed. 34, 1997.

DELEUZE, Gilles; PARNET, Claire. L'abécédaire de Gilles Deleuze, entrevista feita por Claire Parnet, filmada e dirigida por Pierre-André Boutang. Paris: Vidéo Éditions Montparnasse, 1997. In: UNIVERSIDADE DE SÃO PAULO. O abecedário de Gilles Deleuze. Transcrição integral do vídeo para fins exclusivamente didáticos. Disponível em http://stoa.usp.br/prodsubjeduc/files/262/1015/Abecedario+G.+Deleuze.pdf. Acesso em 7 maio 2020.

FONSECA, Tânia Mara Galli et al. O delírio como método: a poética desmedida das singularidades. Estudos e Pesquisas em Psicologia, Rio de Janeiro, ano 10, n. 1, p. 169-189, 2010.

FREIRE, Paulo. Professora, sim; tia não: cartas a quem ousa ensinar. São Paulo: Olho d'água, 1997.

FRÓES BURNHAM, Terezinha. Complexidade, multirreferencialidade e subjetividade: três referências polêmicas para a compreensão do currículo escolar. In: BARBOSA, Joaquim. (org.). Reflexões em torno da abordagem multirreferencial. São Carlos: EDUFSCAR, 1998. p. 35-55.

GALEFFI, Dante. O rigor nas pesquisas qualitativas: uma abordagem fenomenológica em chave transdisciplinar. In: GALEFFI, Dante; MACEDO, Roberto; PIMENTEL, Álamo. (org.). Um rigor outro sobre a qualidade na pesquisa qualitativa: educação e ciência humanas. Salvador: EDUFBA, 2009. p. 13-74.

GALEFFI, Dante; MACEDO, Roberto; PIMENTEL, Álamo. Um rigor outro sobre a qualidade na pesquisa qualitativa: educação e ciência humanas. Salvador: EDUFBA, 2009.

GALEFFI, Dante; SALES, Kathia Marise Borges. Tudo que é real é virtual. Tudo que é virtual é real: considerações sobre a temporalidade mediada. In: ARNOUD, Soares de Lima Júnior. (org.). Educaşão e contemporaneidade: contexto e singularidades. Salvador, EDUFBA, EDUNEB, 2012. p. 103-124. 
GUATTARI, Félix; RONILK, Suely. Micropolítica: cartografias do desejo. 10. ed. Petrópolis: Vozes, 2010.

HOUAISS, Antônio. Dicionário Houaiss. 2017. Disponível em https://houaiss.uol.com.br/pub/apps/www/v3-2/html/index.php\#1. Acesso em 15 mar. 2020.

KASTRUP, Virgínia. O funcionamento da atenção no trabalho do cartógrafo. Psicologia \& Sociedade, Recife, v. 19, n. 1, p. 15-22, jan./abr. 2007. DOI: http://dx.doi.org/10.1590/S0102$\underline{71822007000100003}$

KINCHELOE, Joe Lyons; BERRY, Kathlenn S. Pesquisa em Educação: conceituando a bricolagem. Tradução Roberto Cataldo Costa. Porto Alegre: Artmed, 2007.

LÉVI-STRAUSS, Claude. O pensamento selvagem. São Paulo: Companhia Editora Nacional, 1976.

MACEDO, Roberto Sidnei. Trajetória, itinerário, itinerância e errância no campo do currículo. In: REUNIÃO ANUAL DA ASSOCIAÇÃO NACIONAL DE PÓS-GRADUAÇÃO E PESQUISA EM EDUCAÇÃO - ANPED, 23, 2000, Caxambu. Anais eletrônicos [...]. Caxambu: ANPED, 2000. Disponível em http://23reuniao.anped.org.br/textos/1224t.PDF. Acesso em 3 mar. 2020.

MICHAELIS. Transe. Dicionário Brasileiro da Lingua Portuguesa, 2017. Disponível em http://michaelis.uol.com.br/moderno-portugues/busca/portugues-brasileiro/transe/. Acesso em 3 mar. 2020.

MORIN, Edgar. Amor, poesia e sabedoria. Tradução Ana Paula de Viveiros. Lisboa: Instituto Piaget, 1997.

MORIN, Edgar. Introdução ao pensamento complexo. 3. ed. Porto Alegre: Sulina, 2007.

OLIVEIRA, Thiago Ranniery Moreira de; PARAÍSO, Marlucy Alves. Mapas, dança, desenhos: a cartografia como método de pesquisa em educação. Pro-Posições, Campinas, v. 23, n. 3. p. 159-178, set./dez. 2012.

PELBART, Pál Peter. Um mundo no qual acreditar. Cadernos de Subjetividade, São Paulo, p. 59-62, 1993.

RONILK, Suely. Pensamento, corpo e devir: uma perspectiva ético/estético/política no trabalho acadêmico. Cadernos de Subjetividade, São Paulo, v. 1, n. 2, p. 241-251, fev./set. 1993.

SÁ, Maria Roseli Gomes Brito de. Currículo e formação: atualizações e experiências na construção de existências singulares. In: SÁ, Maria Roseli Gomes Brito de; FARTES, Vera. (org.). Currículo, Formação \& Saberes profissionais: a (re)valorização epistemológica da experiência. Salvador: EDUFBA, 2010. p. 37-61.

SILVA, Tomaz Tadeu da. Um plano de imanência para o currículo. In: TADEU, Tomaz; CORAZZA, Sandra; ZORDAN, Paola. (org.). Linhas de escrita. Belo Horizonte: Autêntica, 2004. p. 127-205.

ULPIANO, Cláudio. Acontecimento e campo de poder. Aula proferida na Escola Senador Correia, em 5 de abril de 1989. Disponível em: http:/ / claudioulpiano.org.br/aulas-transcritas/aula-de-05041989acontecimento-e-campo-do-poder/. Acesso em 20 mar. 2020.

ZAMBENEDETTT, Gustavo; SILVA, Rosane Azevedo Neves da. Cartografia e genealogia: aproximações possíveis para a pesquisa em Psicologia Social. Psicologia \& Sociedade, Recife, v. 23, n. 3, p. 454-463, set./dez. 2011. DOI: http://dx.doi.org/10.1590/S0102-71822011000300002

ZORDAN, Paola Basso M. B. G. Geo-educação: perspectivas virtuais. 2004. 454 f. Tese (Doutorado em Educação). Universidade Federal do Rio Grande do Sul, Porto Alegre, 2004. 
DOI: $10.12957 /$ teias.\%Y.51324

Submetido em maio de 2020

Aprovado em setembro de 2020

\section{Informações da autora}

Verônica Domingues Almeida

Universidade Federal da Bahia (UFBA)

E-mail:veedomingues@gmail.com

ORCID: https://orcid.org/0000-0001-5232-3838

Link Lattes: http://lattes.cnpq.br/1703382988866944 